\title{
Autoantibody detection is not recommended for chronic pancreatitis: a cross-sectional Study of 557 patients
}

\author{
Xiang-Peng Zeng ${ }^{1,2+}$, Ting-Ting Liu ${ }^{3 \dagger}$, Lu Hao ${ }^{4,5 \dagger}$, Lei Xin ${ }^{1,2,5}$, Teng Wang ${ }^{2,5}$, Lin He ${ }^{2}$, Jun Pan ${ }^{2,5}$, Dan Wang ${ }^{2}$, \\ Ya-Wei Bi ${ }^{2}$, Jun-Tao Ji ${ }^{2}$, Zhuan Liao ${ }^{1,2,5}$, Ting-Ting Du², Jin-Huan Lin² ${ }^{2}$ Di Zhang ${ }^{2,5}$, Hong-Lei Guo ${ }^{2}$, Hui Chen ${ }^{1,2,5}$, \\ Wen-Bin Zou ${ }^{2,5}$, Bai-Rong Li ${ }^{6}$, Zhi-Jie Cong ${ }^{7}$, Li-Sheng Wang ${ }^{8}$, Zheng-Lei Xu ${ }^{8}$, Ting Xie ${ }^{9}$, Ming-Hao Liu ${ }^{10}$, \\ An-Mei Deng ${ }^{3 *}$, Zhao-Shen $\mathrm{Li}^{1,2,5^{*}}$ (D) and Liang-Hao Hu ${ }^{1,2,5^{*}}$
}

\begin{abstract}
Background: Autoimmune factor was regarded as one of the risk factors in the pathogenesis of chronic pancreatitis $(C P)$, especially for autoimmune pancreatitis (AIP). However, whether autoimmune factor plays a role in non-AIP CP or not was unknown.

Methods: Hospitalized patients with non-AIP CP from January 2010 to October 2016 were detected for 22 autoantibodies at the time of hospital admission. Autoantibodies with frequency $>0.5 \%$ were enrolled to calculate the frequency in historial healthy controls through literature search in PubMed. Differentially expressed autoantibodies were determined between patients and historial healthy controls, and related factors were identified by multivariate logistic regression analysis.
\end{abstract}

Results: In a total of 557 patients, 113 cases were detected with 19 kinds of positive autoantibodies, among them anti$\beta 2$-glycoprotein I ( $\beta 2$-GPI) antibody was most frequent (9.16\%). Compared with historial healthy controls, the frequencies of serum $\beta 2-G P I$ and anti SS-B antibody in patients were significantly higher, while frequencies of anti-smooth muscle antibody and anticardiolipin antibody were significantly lower (all $P<0.05$ ). Multivariate logistic regression analysis result showed that diabetes mellitus $(\mathrm{OR}=2.515)$ and common bile duct stricture $(\mathrm{OR}=2.844)$ were the risk factors of positive $\beta 2$-GPI antibody in patients while diabetes mellitus in first-/second-/third-degree relatives $(O R=0.266)$ was the protective factor. There were no related factors for other three differentially expressed autoantibodies.

Conclusions: Four autoantibodies were expressed differentially between patients with non-AIP CP and historial healthy controls. Due to limited significance for diagnosis and treatment of chronic pancreatitis, autoantibodies detection is not recommended conventionally unless suspected of AIP.

Keywords: Chronic pancreatitis, Autoantibody, Autoimmune pancreatitis, Anti-ß2-glycoprotein I antibody, Diabetes mellitus

\footnotetext{
*Correspondence: amdeng70@163.com; zhaoshen-li@hotmail.com; lianghaohu@hotmail.com

Xiang-Peng Zeng, Ting-Ting Liu and Lu Hao contributed equally to this study

${ }^{3}$ Department of Laboratory Medicine, Changhai Hospital, The Second Military

Medical University, Shanghai, China

${ }^{1}$ Department of Gastroenterology, Gongli Hospital, The Second Military

Medical University, Shanghai, China

Full list of author information is available at the end of the article
}

(c) The Author(s). 2019 Open Access This article is distributed under the terms of the Creative Commons Attribution 4.0 International License (http://creativecommons.org/licenses/by/4.0/), which permits unrestricted use, distribution, and reproduction in any medium, provided you give appropriate credit to the original author(s) and the source, provide a link to the Creative Commons license, and indicate if changes were made. The Creative Commons Public Domain Dedication waiver (http://creativecommons.org/publicdomain/zero/1.0/) applies to the data made available in this article, unless otherwise stated. 


\section{Background}

Chronic pancreatitis (CP) is a progressive inflammatory disease with irreversible destruction of the pancreatic parenchyma and ductal structures [1-5]. Autoimmune factor was regarded as one of the risk factors in the pathogenesis of CP. In 1995, Yoshida et al. [6] proposed the concept of autoimmune pancreatitis (AIP) to define this particular type of CP. Now autoimmune is regarded as the major definite pathogenesis of AIP, but whether autoimmune factor plays a role in non-AIP CP or not was unknown. Presence of autoantibodies has been included in Japan [7], Korean [8] and Asian [9] clinical diagnostic criteria for AIP, but clinical practice guidelines $[10,11]$ for $\mathrm{CP}$ had not clearly recommended whether autoantibody detection should be a conventional laboratory test or not. In the past few years, novel specific antibodies have emerged to help the diagnosis and differential diagnosis of AIP [12-14]. However, there have been no researches for specific antibodies of non-AIP CP. In the present study, we prospectively detected 22 common autoantibodies in 557 non-AIP CP patients to initially investigate the clinical significance of autoantibody detection.

\section{Methods}

\section{Patient selection}

Patients with CP admitted to the Department of Gastroenterology, Changhai Hospital for the first time from January 2010 to October 2016 were enrolled for the study mainly due to recurrent abdominal pain. For CP patients who did not experience pain, interventions were performed only when complications such as biliary stricture, pancreatic portal hypertension etc. had occurred, whereas diabetes mellitus and/or steatorrhea was not an indication for invasive treatment of $\mathrm{CP}$. All patients underwent serum autoantibody detection at the time of hospital admission. Exclusion criteria were that: 1. Patients were formerly definitely diagnosed with AIP. 2. Combined with systemic lupus erythematosus, rheumatoid arthritis (RA), leukoderma, uarthritis or other autoimmune diseases before admission. 3. Autoimmune diseases were newly diagnosed within thirty days after autoantibody detection.

\section{Data collection and detection of autoantibodies}

The following information was were prospectively collected: demographic data (age, sex, birthplace, et al), course of $\mathrm{CP}$, medical history, history of other diseases, smoking and alcohol history, family history of pancreatic diseases and diabetes mellitus, laboratory and imaging findings, and treatment strategy.

Peripheral venous blood samples were obtained from all enrolled patients at admission to detect 22 common autoantibodies (EUROIMMUN Medical Laboratory Diagnostics
Stock Company, Lübeck, German), whose sensitivity and specificity were provided in (see Additional file 1: Table S1). The distribution tested prior to using parametric tests of all autoantibodies was normal. Serum anti-double-stranded DNA (anti-ds DNA) antibody, anti-single-stranded DNA (anti-ss DNA) antibody, anti-SM antibody, anti-ribonucleoprotein (anti-RNP) antibody, anti SS-A antibody, anti SS-B antibody, anti-Jo-1 antibody, anti-Scl 70 antibody, anti-proliferating cell nuclear antigen antibody, anti-nucleosome antibodies, anti-histone antibody (AHA), anti-ribosomal antibody and anti-PM-Scl antibody were measured by EUROLINE according to the manufacturers' instructions. Serum samples were tested for anti-smooth muscle antibody (SMA), anti-mitochondrial antibody (AMA), anti-neutrophil cytoplasmic antibody and anti-neutrophil perinuclear antibody by indirect immunofluorescence. Serum anti-glomerular basement membrane antibody, anti-proteinase 3 IgG antibody, anti-myeloperoxidase antibody, anti- $\beta 2$-glycoprotein I ( $\beta 2-\mathrm{GPI})$ antibody and anticardiolipin (ACL) antibody were measured by enzyme-linked immunosorbent assay.

\section{Search strategy}

In order to compare the frequency of autoantibodies between non-AIP CP patients and healthy controls, a literature search for autoantibodies with frequency $>0.5 \%$ was performed through PubMed to identify eligible studies published. These literatures had to report the total positive rate of target autoantibody in historial healthy controls, and those literatures which only report the positive rate of some isoforms were excluded. These search strategy, which were defined prospectively, are provided in (see Additional file 1: Table S2). Then the frequency of target autoantibody in historial healthy controls was calculated by sum of cases in all enrolled studies.

\section{Definitions}

The diagnosis of $\mathrm{CP}$ was established according to the Asia-Pacific consensus [15]. The diagnosis of AIP was established according to the Asian diagnostic criteria [9]. Alcoholic chronic pancreatitis (ACP) was diagnosed when alcohol intake exceeded $80 \mathrm{~g} / \mathrm{d}$ for male and $60 \mathrm{~g} / \mathrm{d}$ for female for at least two years in the absence of other causes, respectively $[16,17]$. Heredity chronic pancreatitis was diagnosed when the $\mathrm{CP}$ patient had no less than two first-degree relatives with $\mathrm{CP}$ or recurrent acute pancreatitis, or no less than three second-degree relatives with $\mathrm{CP}$ or recurrent acute pancreatitis [18]. We defined abnormal anatomy of pancreatic duct system (including pancreas divisum and anomalous pancreaticobiliary junction) as an etiology of $\mathrm{CP}$ in our study, although it still remains a controversy [19]. A patient was defined as post-traumatic $\mathrm{CP}$ due to a definite history of 
abdominal trauma with imaging evidence of pancreatic injury and subsequent ductal dilation [20]. CP patients were considered idiopathic chronic pancreatitis (ICP) when none of the above etiologies were found.

\section{Statistical analysis}

All analyses were performed using SPSS software (version 22.0, SPSS Inc.). Categorical variables were expressed as counts (percentages) and compared using the $X^{2}$ test, Fisher exact test or Mann-Whitney U test. Continuous variables were presented as mean \pm standard deviation (SD). Multivariate logistic regression analysis was performed to identify the independent related factors of differentially expressed autoantibodies on the results of univariate analysis screening (factors with a significance level of $P<0.15$ were included in the multivariate analysis). Odds ratio (OR) and $95 \%$ confidence interval (CI) were calculated. Statistical analyses were conducted at a significance level of 0.05 for all analyses.

\section{Results}

\section{General characteristics of Study subjects}

After exclusion of 98 patients, which consists of 91 patients diagnosed with AIP, 3 patients diagnosed with uarthritis, 1 patient diagnosed with leukoderma, and 1 patient newly diagnosed with RA, a total of 575 non-AIP CP patients were finally enrolled in the study, including 393 males and 164 females. Their general characteristics were presented in Table 1 . The mean \pm SD age at the onset and diagnosis of $\mathrm{CP}$ were $36.60 \pm 16.59$ and $41.53 \pm$ 15.22 years old respectively. ICP was most common (70.4\%) in this study.

\section{Comparison of frequency of autoantibodies between non-AIP CP patients and historial healthy controls} In this study, we selected autoantibodies with frequency $>0.5 \%$ ( $\beta 2$-GPI, SMA, ACL, AMA, anti SS-B, anti-ds DNA, anti-ss DNA, AHA, anti-RNP, anti-proteinase 3 IgG antibody) in non-AIP $\mathrm{CP}$ patients as search objects to compare and analyze, which were listed in Table 2. We identified 86 relevant citations through PubMed to be enrolled in this study (Additional file 1: Table S2). Then the frequency of these autoantibodies in non-AIP CP patients and historial healthy controls were calculated and compared respectively. $X^{2}$ or Fisher exact test results showed that the frequencies of serum $\beta 2-$ GPI and anti SS-B antibody in patients were significantly higher than that in historial healthy controls, and the frequencies of serum SMA and ACL antibody in patients were significantly lower than that in historial healthy controls (all $P<0.05$ ).

\section{Related factors for positive $\beta 2$-GPI antibody in non-AIP CP patients}

As there were significant differences in frequency of serum $\beta 2$-GPI, anti SS-B, SMA and ACL antibody between non-AIP $C P$ patients and historial healthy controls, the relationship between these 4 autoantibodies and clinical characteristics were analyzed in non-AIP CP patients. The potential related factors were listed in Table 3 and were analyzed in the univariate analysis. As illustrated in Table 4 , four variables showed a $P$ value less than 0.15 in the univariate logistic regression analysis screening, and they were selected as candidates for multivariate logistic regression analysis. The result showed that diabetes mellitus (DM) in first-/second -/third-degree relatives $(\mathrm{OR}=0.266, P=0.033)$ was the protective factor of positive $\beta 2$-GPI antibody while DM $(\mathrm{OR}=2.768, P=0.001)$ and common bile duct stricture $(\mathrm{OR}=2.952, P=0.007)$ were the risk factors. There were no related factors for other three differentially expressed autoantibodies (all $P>0.05$ ), which were showed in (see Additional file 1: Table S3-S6).

\section{Discussion}

To our knowledge, the current study is the first study to compare the frequency of autoantibodies between non-AIP CP patients and historial healthy controls. This study totally detected 22 autoantibodies in 575 non-AIP $\mathrm{CP}$ patients after exclusion of patients combined with or newly diagnosed of other autoimmune diseases. Four autoantibodies ( $\beta 2$-GPI, anti SS-B, SMA and ACL antibody) were expressed differentially between non-AIP CP patients and historial healthy controls. DM in first-/second-/third-degree relatives was the protective factor of positive $\beta 2$-GPI antibody while DM and common bile duct stricture were the risk factors. And there were no related factors for other three differentially expressed autoantibodies.

$\beta 2-$ GPI antibody, a major antigenic target for antiphospholipid antibodies, was the most frequent autoantibody in non-AIP CP patients. $\beta 2$-GPI antibody could bine to negatively charged phospholipids and inhibit the coagulation cascade and platelet function [21]. Previous study had demonstrated that $\beta 2$-GPI could interact with oxidized low density lipoprotein to form $\beta 2$-GPI-ox-LDL complexes, and serum levels of $\beta 2$-GPI-ox-LDL complexes were significantly elevated in autoimmune disorders, which may reliably help to predict the development of autoimmune-mediated atherosclerosis [22]. This present study showed that frequency of $\beta 2$-GPI antibody in non-AIP CP patients was significantly higher than that in historial healthy controls $(9.16 \%$ vs. $1.97 \%, P<0.001)$. Multivariate logistic regression analysis result showed that $\mathrm{DM}$ and common bile duct stricture were risk factors of positive $\beta 2$-GPI antibody while DM in first/second/third 
Table 1 Clinical characteristics of 557 non-AIP CP patients

\begin{tabular}{|c|c|c|c|}
\hline Items & $\begin{array}{l}\text { Male }(n=393) \\
\mathrm{n}(\%)\end{array}$ & $\begin{array}{l}\text { Female }(n=164) \\
\mathrm{n}(\%)\end{array}$ & $\begin{array}{l}\text { Overall }(n=557) \\
\mathrm{n}(\%)\end{array}$ \\
\hline Body mass index, $\mathrm{kg} / \mathrm{m}^{2 a}$ & $26.56 \pm 105.94$ & $20.89 \pm 3.58$ & $24.89 \pm 89.01$ \\
\hline Age at the onset of $C P, y^{a}$ & $38.89 \pm 15.86$ & $31.09 \pm 17.05$ & $36.60 \pm 16.59$ \\
\hline Age at the diagnosis of $C P, y^{a}$ & $43.60 \pm 14.40$ & $36.57 \pm 16.00$ & $41.53 \pm 15.22$ \\
\hline \multicolumn{4}{|l|}{ Etiology } \\
\hline ACP & $97(24.7)$ & 15(9.1) & $112(20.1)$ \\
\hline $\mathrm{ICP}$ & $266(67.7)$ & 126(76.8) & 392(70.4) \\
\hline Abnormal anatomy of pancreatic duct & $18(4.6)$ & $11(6.7)$ & $29(5.2)$ \\
\hline Hereditary CP & $11(2.8)$ & $11(6.7)$ & $22(3.9)$ \\
\hline Post-traumatic CP & $1(0.3)$ & $1(0.6)$ & $2(0.4)$ \\
\hline Pancreatic stones & $363(92.4)$ & 153(93.3) & $517(92.6)$ \\
\hline Adolescent & $40(10.2)$ & $32(19.5)$ & $72(12.9)$ \\
\hline DM & 102(26.0) & $33(20.1)$ & 135(24.2) \\
\hline Steatorrhea & $91(23.2)$ & $41(25.0)$ & 132(23.7) \\
\hline Common bile duct stricture & $40(10.2)$ & $7(14.9)$ & $47(8.4)$ \\
\hline PPC & 74(18.8) & $20(12.2)$ & $94(16.9)$ \\
\hline SAP & 13(3.3) & $4(2.4)$ & $17(3.0)$ \\
\hline \multicolumn{4}{|l|}{ Onset manifestations } \\
\hline Abdominal pain & $320(81.4)$ & 116(70.7) & $436(78.3)$ \\
\hline Pancreatic insufficiency & $53(13.5)$ & $35(21.3)$ & $88(15.8)$ \\
\hline Others & $20(5.1)$ & $13(7.9)$ & $33(5.9)$ \\
\hline \multicolumn{4}{|l|}{ Type of abdominal pain } \\
\hline None & $31(7.9)$ & 26(15.9) & $57(10.2)$ \\
\hline Repeat attacks of acute pancreatitis & $120(30.5)$ & $45(27.4)$ & 165(29.6) \\
\hline Repeat pain & 138(35.1) & $57(34.8)$ & 195(35.0) \\
\hline Repeat acute attacks and pain & $71(18.1)$ & $25(15.2)$ & $96(17.2)$ \\
\hline Chronic pain & $33(8.4)$ & $11(6.7)$ & $44(7.9)$ \\
\hline \multicolumn{4}{|l|}{ Drinking history (g/d) } \\
\hline 0 & $223(56.7)$ & 130(79.3) & $353(63.4)$ \\
\hline$<20$ & 13(3.3) & $5(3.0)$ & 18(3.2) \\
\hline $20 \sim 80$ & $53(13.5)$ & $10(6.1)$ & $63(11.3)$ \\
\hline$>80$ & 104(26.5) & 19(11.6) & $123(22.1)^{b}$ \\
\hline \multicolumn{4}{|l|}{ Smoking history, pack-year } \\
\hline 0 & 212(53.9) & 130(79.3) & $342(61.4)$ \\
\hline$<60$ & $161(41.0)$ & $32(19.5)$ & 193(34.6) \\
\hline$\geq 60$ & 20(5.1) & 2(1.2) & $22(3.9)$ \\
\hline DM in first-/second-/third-degree relatives & $57(14.5)$ & 28(17.1) & $85(15.3)$ \\
\hline Pancreatic diseases in first-/second-/third-degree relatives & $12(3.1)$ & $7(4.3)$ & 19(3.4) \\
\hline Elevated $\lg G^{c}$ & $16(4.1)$ & $3(1.8)$ & 19(3.4) \\
\hline Elevated $\lg G 4^{c}$ & 19(4.8) & $2(1.2)$ & 21(3.8) \\
\hline
\end{tabular}

CP Chronic pancreatitis, ACP Alcoholic chronic pancreatitis, AIP Autoimmune pancreatitis, ICP Idiopathic chronic pancreatitis, DM Diabetes mellitus, PPC Pancreatic pseudocyst, SAP Severe acute pancreatitis

${ }^{\mathrm{a}}$ Mean \pm SD

${ }^{\mathrm{b}} 123$ patients with drinking history $>80 \mathrm{~g} / \mathrm{d}$ included 112 cases with $\mathrm{ACP}, 7$ cases with hereditary $\mathrm{CP}, 3$ cases with anatomical abnormality and one case with post-traumatic CP

'Serum IgG and IgG4 were measured by immunoturbidimetry assay (Immage800 specific protein analyzer, Beckman, USA; BN2 specific protein analyzer, Siemens, Germany), and their upper limits were $15.6 \mathrm{~g} / \mathrm{l}$ and $2.0 \mathrm{~g} / \mathrm{l}$ respectively 
Table 2 Comparison of positive rate of nine autoantibodies between non-AIP CP patients and historial healthy controls

\begin{tabular}{|c|c|c|c|c|c|c|c|}
\hline \multirow[t]{2}{*}{ Autoantibody } & \multicolumn{3}{|c|}{ non-AIP CP patients } & \multicolumn{3}{|c|}{ Historial Healthy controls } & \multirow[t]{2}{*}{$P$} \\
\hline & Positive & Negative & Frequency (\%) & Positive & Negative & Frequency (\%) & \\
\hline Anti- $\beta 2$-glycoprotein I antibody & 51 & 506 & 9.16 & 37 & 1839 & 1.97 & $<0.001$ \\
\hline Anti-smooth muscle antibody & 17 & 540 & 3.05 & 24 & 302 & 7.36 & 0.003 \\
\hline Anticardiolipin antibody & 16 & 541 & 2.87 & 93 & 1431 & 6.10 & 0.003 \\
\hline Anti-mitochondrial antibody & 9 & 548 & 1.62 & 14 & 1340 & 1.03 & 0.224 \\
\hline Anti SS-B antibody & 9 & 548 & 1.62 & 4 & 1659 & 0.24 & $<0.001$ \\
\hline Anti-double-stranded DNA antibody & 8 & 549 & 1.44 & 0 & 202 & 0 & 0.190 \\
\hline Anti-single-stranded DNA antibody & 6 & 551 & 1.08 & 14 & 568 & 2.41 & 0.088 \\
\hline Anti-histone antibody & 5 & 552 & 0.90 & 14 & 711 & 1.93 & 0.129 \\
\hline Anti-ribonucleoprotein antibody & 3 & 554 & 0.54 & 13 & 1078 & 1.19 & 0.201 \\
\hline Anti-proteinase 3 lgG antibody & 3 & 554 & 0.54 & 0 & 237 & 0 & 0.558 \\
\hline Anti-PM-Scl antibody & 2 & 555 & 0.36 & - & - & - & - \\
\hline Anti-neutrophil cytoplasmic antibody & 2 & 555 & 0.36 & - & - & - & - \\
\hline Anti-ribosomal antibody & 2 & 555 & 0.36 & - & - & - & - \\
\hline Anti SS-A antibody & 1 & 556 & 0.18 & - & - & - & - \\
\hline Anti-Jo-1 antibody & 1 & 556 & 0.18 & - & - & - & - \\
\hline Anti-SM antibody & 1 & 556 & 0.18 & - & - & - & - \\
\hline Anti-myeloperoxidase antibody & 1 & 556 & 0.18 & - & - & - & - \\
\hline anti-neutrophil perinuclear antibody & 1 & 556 & 0.18 & - & - & - & - \\
\hline Anti-proliferating cell nuclear antigen antibody & 1 & 556 & 0.18 & - & - & - & - \\
\hline Anti-Scl 70 antibody & 0 & 556 & 0 & - & - & - & - \\
\hline Anti-nucleosome antibodies & 0 & 556 & 0 & - & - & - & - \\
\hline Anti-glomerular basement membrane antibody & 0 & 556 & 0 & - & - & - & - \\
\hline
\end{tabular}

$C P$ Chronic pancreatitis, AIP Autoimmune pancreatitis

degree relatives was a protective factor. But there is no previous study to confirm the relationship between $\beta 2-$ GPI antibody and family history of DM, CBD stricture. Only a few studies have showed that $\beta 2$-GPI antibody may participate in the occurrence and development of DM [23]. Cojocaru et al. [24] indicated that the positive rate of anti-IgG $\beta 2$-GPI in type 2 diabetes mellitus patients with diabetic retinopathy (DR) was significantly higher than that in patients without DR ( $85 \%$ vs. $21 \%$, RR 4.640). However, Tarkun et al. [25] found that there was no significant association between $\beta 2$-GPI antibody and vascular complications in type 2 diabetes mellitus patients, so $\beta 2$-GPI antibody may not have a major role in the pathogenesis of diabetic complications in type 2 diabetes mellitus patients. In brief, it's unclear whether $\beta 2$-GPI antibody was related to the occurrence and development of clinical events of $\mathrm{CP}$ until now.

At present, CP is regarded as a disease with multiple etiological factors including alcohol, autoimmunity, biliary tract diseases, etc. And alcohol and autoimmunity factors may coexist. In the past, patients suspected of $\mathrm{CP}$ admitted to our center for the first time would be received history taking, physical examination, imaging examination and laboratory examination (including serum autoantibody detection) for diagnosis, etiology identification, treatment guidance and prognosis evaluation. The present study determined four differentially expressed autoantibodies between non-AIP CP patients and historial healthy controls, among them $\beta 2$-GPI antibody were expressed most frequently. As $\beta 2$-GPI antibody was independently associated with DM and common bile duct stricture, it may be a potential serum marker to predict the occurrence of these clinical events. Although previous studies found several serum markers for early diagnosis [26] and differential diagnosis [27] of $\mathrm{CP}$, they were not widely used in clinic practice. Until now, the diagnosis of $\mathrm{CP}$ is mainly based on the clinical manifestation and imaging findings. Although this current study identified four differentially expressed autoantibodies between non-AIP CP patients and historial healthy controls, they had limited value in diagnosing non-AIP CP, and could not help the differentiation of non-AIP CP from other pancreatic diseases including pancreatic cancer, intraductal papillary mucinous neoplasm of the pancreas, cystic pancreatic lesions and so on because of low specificity [28]. And there is no 
Table 3 Related factors for positive $\beta 2-$ GPI antibody in non-AIP CP patients [n(\%)]

\begin{tabular}{|c|c|c|c|}
\hline Predictors & $\operatorname{Positiven}(n=51)$ & Negetive $(n=506)$ & $P$ \\
\hline Female sex & 15(29.4) & 149(29.4) & 0.996 \\
\hline $\mathrm{BMI}, \mathrm{kg} / \mathrm{m}^{2}$ & $21.49 \pm 3.06^{\mathrm{a}}$ & $25.23 \pm 93.39$ & 0.775 \\
\hline Age at the onset of $C P, y^{a}$ & $40.31 \pm 18.54^{\mathrm{a}}$ & $36.22 \pm 16.36$ & 0.093 \\
\hline Age at the diagnosis of $C P, y^{a}$ & $46.09 \pm 15.33^{a}$ & $41.07 \pm 15.15$ & 0.135 \\
\hline Etiology & & & 0.410 \\
\hline $\mathrm{ACP}$ & 6(11.8) & 106(20.9) & \\
\hline ICP & $41(80.4)$ & $351(69.4)$ & \\
\hline Abnormal anatomy of pancreatic duct & $1(2.0)$ & $28(5.5)$ & \\
\hline Hereditary CP & $3(5.9)$ & 19(3.8) & \\
\hline Post-traumatic CP & $0(0)$ & $2(0.4)$ & \\
\hline Pancreatic stones & $46(90.2)$ & $470(92.9)$ & 0.675 \\
\hline Adolescent & $5(9.8)$ & $67(13.2)$ & 0.486 \\
\hline DM & $22(43.1)$ & $113(22.3)$ & 0.001 \\
\hline Steatorrhea & $14(27.5)$ & 118(23.3) & 0.508 \\
\hline Common bile duct stricture & 11(19.6) & $37(7.3)$ & 0.006 \\
\hline PPC & $8(15.7)$ & $86(17.0)$ & 0.812 \\
\hline SAP & 2(3.9) & $15(3.0)$ & 1.000 \\
\hline Onset manifestations & & & 0.110 \\
\hline Abdominal pain & $35(68.6)$ & $401(79.2)$ & \\
\hline Pancreatic insufficiency & 10(19.6) & $78(15.4)$ & \\
\hline Others & $6(11.8)$ & $27(5.3)$ & \\
\hline Type of pain & & & 0.576 \\
\hline None & $7(13.7)$ & $50(9.9)$ & \\
\hline Repeat attacks of acute pancreatitis & $14(27.5)$ & 151(29.8) & \\
\hline Repeat pain & $21(41.2)$ & 174(34.4) & \\
\hline Repeat acute attacks and pain & $7(13.7)$ & $89(17.6)$ & \\
\hline Chronic pain & 2(3.9) & $42(8.3)$ & \\
\hline Drinking history (g/d) & & & 0.078 \\
\hline 0 & $38(74.5)$ & $315(62.3)$ & \\
\hline$<20$ & $1(2.0)$ & $17(3.4)$ & \\
\hline $20 \sim 80$ & $5(9.8)$ & $58(11.5)$ & \\
\hline$>80$ & $7(13.7)$ & $116(22.9)$ & \\
\hline Smoking history, pack-year & & & 0.020 \\
\hline 0 & $39(76.5)$ & $303(59.9)$ & \\
\hline$<60$ & $11(21.6)$ & 182(36.0) & \\
\hline$\geq 60$ & $1(2.0)$ & $21(4.2)$ & \\
\hline DM in first-/second-/third-degree relatives & 3(5.9) & $82(16.2)$ & 0.051 \\
\hline Pancreatic diseases in first-/second-/third-degree relatives & $0(0)$ & 19(3.8) & 0.316 \\
\hline Elevated lgG & 3(5.9) & $16(3.2)$ & 0.538 \\
\hline Elevated $\lg G 4^{b}$ & $5(9.8)$ & $16(3.2)$ & 0.047 \\
\hline
\end{tabular}

CP Chronic pancreatitis, ACP Alcoholic chronic pancreatitis, AIP Autoimmune pancreatitis, ICP Idiopathic chronic pancreatitis, DM Diabetes mellitus, PPC Pancreatic pseudocyst, SAP Severe acute pancreatitis

${ }^{\mathrm{a}}$ Mean $\pm \mathrm{SD}$

${ }^{\mathrm{b}}$ Serum IgG and IgG4 were measured by immunoturbidimetry assay (Immage800 specific protein analyzer, Beckman, USA; BN2 specific protein analyzer, Siemens, Germany), and their upper limits were $15.6 \mathrm{~g} / \mathrm{l}, 2.0 \mathrm{~g} / \mathrm{l}$ respectively 
Table 4 Related factors for positive $\beta 2-G P I$ antibody in non-AIP CP patients

\begin{tabular}{|c|c|c|c|c|}
\hline \multirow[t]{2}{*}{ Predictors } & \multicolumn{2}{|l|}{ Univariate Analysis } & \multicolumn{2}{|l|}{ Multivariate Analysis } \\
\hline & $\mathrm{OR}(95 \% \mathrm{Cl})$ & $P$ & $\mathrm{OR}(95 \% \mathrm{Cl})$ & $P$ \\
\hline Female sex & $1.042(0.509-2.130)$ & 0.911 & & \\
\hline $\mathrm{BMI}, \mathrm{kg} / \mathrm{m}^{2}$ & 0.998(0.987-1.009) & 0.751 & & \\
\hline Age at the onset of $C P, y^{a}$ & $0.992(0.954-1.031)$ & 0.684 & & \\
\hline Age at the diagnosis of $\mathrm{CP}, \mathrm{y}^{\mathrm{a}}$ & $1.028(0.986-1.071)$ & 0.195 & & \\
\hline Etiology & & 0.812 & & \\
\hline $\mathrm{ACP}$ & Control & & & \\
\hline ICP & $0.991(0.059-16.668)$ & 0.995 & & \\
\hline Abnormal anatomy of pancreatic duct & $0.377(0.013-11.052)$ & 0.571 & & \\
\hline Hereditary CP & $1.770(0.164-19.055)$ & 0.638 & & \\
\hline Post-traumatic CP & $0(0)$ & 0.999 & & \\
\hline Pancreatic stones & $0.680(0.220-2.103)$ & 0.503 & & \\
\hline Adolescent & $1.167(0.318-4.284)$ & 0.816 & & \\
\hline DM & $2.315(1.174-4.566)$ & 0.015 & $2.768(1.510-5.072)$ & 0.001 \\
\hline Steatorrhea & $1.462(0.705-3.033)$ & 0.307 & & \\
\hline Common bile duct stricture & 2.785(1.159-6.693) & 0.022 & 2.952(1.343-6.489) & 0.007 \\
\hline PPC & $0.938(0.397-2.215)$ & 0.883 & & \\
\hline SAP & $0.906(0.160-5.139)$ & 0.911 & & \\
\hline Onset manifestations & & 0.240 & & \\
\hline Abdominal pain & Control & & & \\
\hline Pancreatic insufficiency & $1.081(0.414-2.821)$ & 0.874 & & \\
\hline Others & $2.949(0.780-11.145)$ & 0.111 & & \\
\hline Type of pain & & 0.879 & & \\
\hline None & Control & & & \\
\hline Repeat attacks of acute pancreatitis & $1.131(0.292-4.377)$ & 0.858 & & \\
\hline Repeat pain & $1.121(0.331-3.797)$ & 0.854 & & \\
\hline Repeat acute attacks and pain & $1.132(0.245-5.243)$ & 0.874 & & \\
\hline Chronic pain & $0.470(0.070-3.155)$ & 0.437 & & \\
\hline Drinking history (g/d) & & 0.828 & & \\
\hline 0 & Control & & & \\
\hline$<20$ & $0.488(0.056-4.282)$ & 0.517 & & \\
\hline $20 \sim 80$ & $0.649(0.209-2.138)$ & 0.497 & & \\
\hline$>80$ & $0.634(0.043-9.452)$ & 0.741 & & \\
\hline Smoking history, pack-year & & 0.445 & & \\
\hline 0 & Control & & & \\
\hline$<60$ & $0.565(0.230-1.386)$ & 0.213 & & \\
\hline$\geq 60$ & $0.533(0.058-4.928)$ & 0.579 & & \\
\hline DM in first-/second-/third-degree relatives & $0.272(0.076-0.076)$ & 0.045 & $0.266(0.079-0.897)$ & 0.033 \\
\hline Pancreatic diseases in first-/second-/third-degree relatives & $0(0)$ & 0.999 & & \\
\hline Elevated $\lg G^{b}$ & $1.639(0.409-6.564)$ & 0.485 & & \\
\hline Elevated $\operatorname{lgG} 4^{\mathrm{b}}$ & $2.797(0.814-9.614)$ & 0.103 & & \\
\hline
\end{tabular}

CP Chronic pancreatitis, ACP Alcoholic chronic pancreatitis, AIP Autoimmune pancreatitis; ICP Idiopathic chronic pancreatitis, DM Diabetes mellitus, PPC Pancreatic pseudocyst, SAP Severe acute pancreatitis

${ }^{\mathrm{a}}$ Mean $\pm \mathrm{SD}$

${ }^{\mathrm{b} S e r u m ~ I g G ~ a n d ~ I g G 4 ~ w e r e ~ m e a s u r e d ~ b y ~ i m m u n o t u r b i d i m e t r y ~ a s s a y ~(I m m a g e 800 ~ s p e c i f i c ~ p r o t e i n ~ a n a l y z e r, ~ B e c k m a n, ~ U S A ; ~ B N 2 ~ s p e c i f i c ~ p r o t e i n ~ a n a l y z e r, ~ S i e m e n s, ~}$ Germany), and their upper limits were $15.6 \mathrm{~g} / \mathrm{l}, 2.0 \mathrm{~g} / \mathrm{l}$ respectively 
research to confirm that these four autoantibodies are protective against development of $\mathrm{CP}$ up to now. Therefore, we don't recommend that autoantibodies test should be a conventional examination for diagnosis and differential diagnosis of CP unless suspected of AIP, whose several diagnostic criteria [7-9] had include presence of autoantibodies. Another recent study in our center showed that the positive rates of antinuclear antibody, anti-SSA antibody, and anti-SSB antibody of patients with AIP were 17.1, 11.4 and 8.6\% respectively, and then we considered that autoantibody could be a subsidiary indicator for the diagnosis of AIP [29]. Treatment options of CP mainly include pancreatic enzyme replacement therapy, insulin infusion injection, endoscopic therapy and surgery, which were mostly determined by clinical symptom, blood sugar level, imaging findings and patients' subjective will. Although the presence of autoantibodies were related with DM and common bile duct stricture in this present study, they could not be served as predictors for the clinical events, and had little significance in guiding clinical treatments and evaluating curative effect until now.

There are several limitations of the present study. Firstly, the observational study design (cohort study) is inherent to selection bias. And we chose control group through literature search in PubMed due to difficulty for large-scale collecting the serum of healthy people to detect all antibodies in clinical, but the historial healthy controls may increase the inaccuracy of target autoantibodies' frequencies as there may be differences among different races, countries, regions and nations. Secondly, this study lack of estimate on causality between autoantibody and CP occurrence as the samples were tested once disease had occurred. Thirdly, this current study belongs to cross-sectional study, so it is not clearly whether autoantibody test could predict the occurrence of clinical events and treatment prognosis of CP.

\section{Conclusions}

Four autoantibodies were expressed differentially between non-AIP CP patients and historial healthy controls. Due to limited significance for diagnosis and treatment of CP, autoantibodies detection is not recommended conventionally unless suspected of AIP.

\section{Additional file}

Additional file 1: Table S1. Sensitivity and specificity of test method of 22 autoantibodies. Peripheral venous blood samples were obtained from all enrolled patients at admission to detect 22 common autoantibodies (EUROIMMUN Medical Laboratory Diagnostics Stock Company, Lübeck, German), whose sensitivity and specificity were provided in Additional file 1: Table S1. Table S2. Search strategy and result in PubMed (up until May 4th, 2017) In order to compare the frequency of autoantibodies between non-AIP CP patients and healthy controls, a literature search for autoantibodies with frequency $>0.5 \%$ was performed through PubMed to identify eligible studies published. These search strategy and result are provided in Additional file 1: Table S2. Table S3. Univariate analysis for smooth muscle antibody, anticardiolipin antibody and anti SS-B antibody in non-AIP CP patients [n(\%)]. Univariate analysis result showed that there were no significant differences in all clinical data between patients with positive and negative other three differentially expressed autoantibodies (smooth muscle antibody, anticardiolipin antibody and anti SS-B antibody) (all $P>0.05$ ). Table S4. Related factors for positive smooth muscle antibody in non-AIP CP patients. Univariate logistic regression analysis result showed that there were no related factors for positive smooth muscle antibody in non-AIP CP patients $(P>0.05)$. Table S5. Related factors for positive anticardiolipin antibody in non-AIP CP patients. Univariate logistic regression analysis result showed that there were no related factors for positive anticardiolipin antibody in non-AIP CP patients $(P>0.05)$. Table S6. Related factors for positive anti SS-B antibody in non-AIP CP patients. Univariate logistic regression analysis result showed that there were no related factors for positive anti SS-B antibody in non-AIP CP patients $(P>0.05)$. (DOCX $165 \mathrm{~kb})$

\section{Abbreviations}

ACL: Anticardiolipin; ACP: Alcoholic chronic pancreatitis; AHA: Anti-histone antibody; AIP: Autoimmune pancreatitis; AMA: Anti-mitochondrial antibody; Anti-ds DNA: Anti-double-stranded DNA; Anti-RNP: Anti-ribonucleoprotein; Anti-ss DNA: Anti-single-stranded DNA; Cl: Confidence interval; CP: Chronic pancreatitis; DM: Diabetes mellitus; DR: Diabetic retinopathy; ICP: Idiopathic chronic pancreatitis; OR: Odds ratio; PPC: Pancreatic pseudocyst; RA: Rheumatoid arthritis; SAP: Severe acute pancreatitis; SD: Standard deviation; SMA: Anti-smooth muscle antibody; $\beta 2-$ GPI: Anti- $\beta 2$-glycoprotein I

\section{Acknowledgements}

Not applicable.

\section{Funding}

This study was supported by the National Natural Science Foundation of China [Grant Nos. 81500490 (BRL), 81770635 (LHH), 81470883 (LHH), 81770632 (LX) and 81600439 (ZJC)], Three engineering training funds in Shenzhen [Grant No. SYJY201713 (LSW)], Special Foundation for Wisdom Medicine of Shanghai [Grant No. 2018ZHYL0229 (LHH)], and Clinical Medicine Summit Project of Shanghai Pudong District [Grant No. PWYGF2018-01 (LSW)] in data acquisition and manuscript drafting, Shanghai Rising-Star Program [Grant No. 17QA 1405500 (LHH)], Shanghai Youth Top-notch Talent Program [Grant No. HZW2016FZ67 (LHH)], Shanghai Excellent Young Medical Talents Program [Grant No. 2018YQ49 (LX)], and Medicine Guidance Project of Shanghai [Grant No. 17411971500 (LX)], in conception design, data interpretation, and manuscript revise.

\section{Availability of data and materials}

The datasets used and/or analyzed during the current study are available from the corresponding author on reasonable request.

\section{Authors' contributions}

$X P Z, T L, L$ Hao participated in the acquisition, analysis, and interpretation of data, as well as in the manuscript drafting; LX, TW, L He, JP, DW, YWB, JTJ, ZL, TTD, JHL, DZ, HLG, HC, WBZ, BRL, ZJC, LSW, ZLX, TX. and MHL participated in data acquisition and manuscript drafting; AMD, LHH and ZSL contributed to the conception, design, and data interpretation, as well as revised the manuscript for important intellectual content. All authors have read and approved the manuscript, and ensure that this is the case.

\section{Ethics approval and consent to participate}

Written informed consent was obtained from all participating patients. The study was approved by the Ethics Committee of Changhai Hospital.

\section{Consent for publication}

Not applicable.

\section{Competing interests}

The authors declare that they have no competing interests. 


\section{Publisher's Note}

Springer Nature remains neutral with regard to jurisdictional claims in published maps and institutional affiliations.

\section{Author details}

'Department of Gastroenterology, Gongli Hospital, The Second Military Medical University, Shanghai, China. ${ }^{2}$ Department of Gastroenterology, Changhai Hospital, The Second Military Medical University, Shanghai, China. ${ }^{3}$ Department of Laboratory Medicine, Changhai Hospital, The Second Military Medical University, Shanghai, China. ${ }^{4}$ Department of Gastroenterology, Hainan Branch of Chinese PLA General Hospital, Sanya, China. ${ }^{5}$ Digestive Endoscopy Center, Changhai Hospital, The Second Military Medical University, Shanghai, China. ${ }^{6}$ Department of Gastroenterology, Air Force General Hospital, Beijing, China. ${ }^{7}$ Department of General Surgery, Renji Hospital, Shanghai Jiaotong University, Shanghai, China. ${ }^{8}$ Department of Gastroenterology, Shenzhen People's Hospital, Shenzhen, China. ${ }^{9}$ Department of Gastroenterology, Zhongda Hospital, Southeast University, Nanjing, China. ${ }^{10}$ Department of Gastroenterology, PLA Rocket Force Characteristic Medical Center, Beijing, China.

Received: 19 September 2018 Accepted: 30 January 2019 Published online: 14 February 2019

\section{References}

1. Nagar N, Dubale N, Jagadeesh R, Nag P, Reddy ND, Rao G. Unusual locations of pseudo aneurysms as a sequel of chronic pancreatitis. $J$ Intervent Gastroenterol. 2011;1(1):28-32.

2. Hao L, Wang T, He L, Bi YW, Zhang D, Zeng XP, et al. Risk factor for steatorrhea in pediatric chronic pancreatitis patients. BMC Gastroenterol. 2018;18(1):182

3. Zeng XP, Zhu XY, Li BR, Pan CS, Hao L, Pan J, et al. Spatial distribution of pancreatic stones in chronic pancreatitis. Pancreas. 2018;47(7):864-70.

4. Hao L, Zeng XP, Xin L, Wang D, Pan J, Bi YW, et al. Incidence of and risk factors for pancreatic cancer in chronic pancreatitis: a cohort of 1656 patients. Dig Liver Dis. 2017;49(11):1249-56.

5. Wang D, Bi YW, Ji JT, Xin L, Pan J, Liao Z, et al. Extracorporeal shock wave lithotripsy is safe and effective for pediatric patients with chronic pancreatitis. Endoscopy. 2017:49(5):447-55.

6. Yoshida K, Toki F, Takeuchi T, Watanabe S, Shiratori K, Hayashi N. Chronic pancreatitis caused by an autoimmune abnormality. Proposal of the concept of autoimmune pancreatitis. Dig Dis Sci. 1995;40(7):1561-8.

7. Okazaki K, Kawa S, Kamisawa T, Naruse S, Tanaka S, Nishimori I, et al. Clinical diagnostic criteria of autoimmune pancreatitis: revised proposal. J Gastroenterol. 2006;41(7):626-31.

8. Kim KP, Kim MH, Kim JC, Lee SS, Seo DW, Lee SK. Diagnostic criteria for autoimmune chronic pancreatitis revisited. World J Gastroenterol. 2006; 12(16):2487-96.

9. Otsuki M, Chung JB, Okazaki K, Kim MH, Kamisawa T, Kawa S, et al. Asian diagnostic criteria for autoimmune pancreatitis: consensus of the JapanKorea symposium on autoimmune pancreatitis. J Gastroenterol. 2008;43(6): 403-8.

10. Ito T, Ishiguro H, Ohara H, Kamisawa T, Sakagami J, Sata N, et al. Evidencebased clinical practice guidelines for chronic pancreatitis 2015. J Gastroenterol. 2016;51(2):85-92.

11. Lohr JM, Dominguez-Munoz E, Rosendahl J, Besselink M, Mayerle J, Lerch MM, et al. United European gastroenterology evidence-based guidelines for the diagnosis and therapy of chronic pancreatitis (HaPanEU). United European Gastroenterol J. 2017;5(2):153-99.

12. Lohr JM, Faissner R, Koczan D, Bewerunge P, Bassi C, Brors B, et al. Autoantibodies against the exocrine pancreas in autoimmune pancreatitis: gene and protein expression profiling and immunoassays identify pancreatic enzymes as a major target of the inflammatory process. Am J Gastroenterol. 2010;105(9):2060-71.

13. Hao M, Li W, Yi L, Yu S, Fan G, Lu T, et al. Hybrid kappa\lambda antibody is a new serological marker to diagnose autoimmune pancreatitis and differentiate it from pancreatic cancer. Sci Rep. 2016;6:27415.

14. Frulloni L, Lunardi C, Simone R, Dolcino M, Scattolini C, Falconi M, et al. Identification of a novel antibody associated with autoimmune pancreatitis. N Engl J Med. 2009;361(22):2135-42.

15. Tandon RK, Sato N, Garg PK, Consensus Study G. Chronic pancreatitis: AsiaPacific consensus report. J Gastroenterol Hepatol. 2002;17(4):508-18.
16. Howes N, Lerch MM, Greenhalf W, Stocken DD, Ellis I, Simon P, et al. Clinical and genetic characteristics of hereditary pancreatitis in Europe. Clin Gastroenterol Hepatol. 2004;2(3):252-61.

17. Wang W, Guo Y, Liao Z, Zou DW, Jin ZD, Zou DJ, et al. Occurrence of and risk factors for diabetes mellitus in Chinese patients with chronic pancreatitis. Pancreas. 2011;40(2):206-12.

18. Lu WF. ERCP and CT diagnosis of pancreas divisum and its relation to etiology of chronic pancreatitis. World J Gastroenterol. 1998;4(2):150-2.

19. Yadav D, Pitchumoni CS. Issues in hyperlipidemic pancreatitis. J Clin Gastroenterol. 2003;36(1):54-62.

20. Bradley EL 3rd. Chronic obstructive pancreatitis as a delayed complication of pancreatic trauma. HPB Surg. 1991;5(1):49-59 discussion -60.

21. Matsuura E, Igarashi Y, Fujimoto M, Ichikawa K, Suzuki T, Sumida T, et al. Heterogeneity of anticardiolipin antibodies defined by the anticardiolipin cofactor. J Immunol. 1992;148(12):3885-91.

22. Matsuura E, Kobayashi K, Inoue K, Lopez LR, Shoenfeld Y. Oxidized LDL/ beta2-glycoprotein I complexes: new aspects in atherosclerosis. Lupus. 2005; 14(9):736-41.

23. Wang C, Niu DM, Hu J, Guan XC, Yang W, Wang JJ, et al. Elevated serum beta2-glycoprotein-l-lipoprotein(a) complexes levels are associated with the presence and complications in type 2 diabetes mellitus. Diabetes Res Clin Pract. 2013:100(2):250-6.

24. Cojocaru IM, Cojocaru M, Popescu AN, Popescu L, Tanasescu R. Study of antiphospholipid antibodies in type 2 diabetes mellitus with and without diabetic retinopathy. Rom J Intern Med. 2009;47(3):267-71.

25. Tarkun I, Hacihanefioglu A, Tarkun P, Cetinarslan B, Canturk Z. Anticardiolipin and anti-beta2 glycoprotein I antibody concentrations in patients with type 2 diabetes mellitus. Diabetes Res Clin Pract. 2005;68(3):181-7.

26. Xin L, Gao J, Wang D, Lin JH, Liao Z, Ji JT, et al. Novel blood-based microRNA biomarker panel for early diagnosis of chronic pancreatitis. Sci Rep. 2017;7:40019.

27. Ghassem-Zadeh S, Gaida MM, Szanyi S, Acha-Orbea H, Frossard JL, Hinz U, et al. Distinct pathophysiological cytokine profiles for discrimination between autoimmune pancreatitis, chronic pancreatitis and pancreatic ductal adenocarcinoma. J Transl Med. 2017;15(1):126

28. Kamisawa T, Chari ST, Lerch MM, Kim MH, Gress TM, Shimosegawa T. Recent advances in autoimmune pancreatitis: type 1 and type 2. Gut. 2013;62(9): 1373-80.

29. Xin L, He YX, Zhu XF, Zhang QH, Hu LH, Zou DW, et al. Diagnosis and treatment of autoimmune pancreatitis: experience with 100 patients. Hepatobiliary Pancreat Dis Int. 2014;13(6):642-8.
Ready to submit your research? Choose BMC and benefit from:
- fast, convenient online submission
- thorough peer review by experienced researchers in your field
- rapid publication on acceptance
- support for research data, including large and complex data types
- gold Open Access which fosters wider collaboration and increased citations
- maximum visibility for your research: over $100 \mathrm{M}$ website views per year
At $\mathrm{BMC}$, research is always in progress.
Learn more biomedcentral.com/submissions 